\title{
A Hybrid Switching Inverter for High -Efficiency Traction Motor Drives
}

\author{
Juluri Shiva Prasad ${ }^{1}$, Narra Narender Reddy ${ }^{2}$ \\ ${ }^{1}$ Sri Venkateswara Engineering College, Suryapet, Nalgonda District, Telangana State, India \\ ${ }^{2}$ Assistant professor, Sri Venkateswara Engineering College, Suryapet Nalgonda District, Telangana State, India
}

\begin{abstract}
This paper presents a hybrid switch which parallels a power MOSFET and an insulated-gate bipolar transistor (IGBT) as the main switch of a zero-voltage switching (ZVS) inverter. In this combination MOSFET is conducting in the low-current region and the IGBT conducting in the high-current region, and the soft switching avoids the reverse recovery problem during the device turn-on. A custom hybrid switch module has been developed for a variable-timing-controlled coupled-magnetic-type ZVS inverter with a nominal input voltage of $325 \mathrm{~V}$ and the continuous output power of $30 \mathrm{~kW}$ for a traction motor drive. The results of the hybrid-switchbased inverter with the total loss shows that the inverter achieves $99 \%$ efficiency at the nominal condition and demonstrate ultrahighefficiency operation over a wide load range. At 375-V input, the maximum measured efficiency through temperature projection and loss separation analysis is $99.3 \%$.
\end{abstract}

Keywords: High efficiency, Electric vehicles, hybrid switch, motor drives, soft-switching inverter.

\section{Introduction}

A soft-switching inverter allows reduces switching loss; however, its conduction loss remains as the major part of the overall loss. If we use power MOSFET as switching device, it is possible to parallel a large number of power MOSFETs to reduce the conduction voltage drop. The problems with more number of paralleled MOSFETs are high cost and increased voltage drop at high temperatures. Thus ,most high-power inverters have been using the IGBT.

In high-power dc-dc converter applications, using IGBT as the main switch and MOSFET as the auxiliary switch, whether series- or parallel-connected [1], [2], improves efficiency. The profit of reducing the conduction loss with parallel-connected IGBT and MOSFET hybrid switch configuration was extensively evaluated in [3]-[5]. In [6], the use of a parallel-connected hybrid switch was configured with the hybrid switch serving as the main switch that operates in low frequency, with each switch operating in linefrequency square-wave mode and the neutral connected IGBT and diode combination operating in high frequency to allow pulse width modulation (PWM) operation. An inverter draws ac sinusoidal current, which runs from zero to positive or negative peak and back down to zero. Its low-current region will consume a high conduction loss if an IGBT is used as the main switch because of its fixed voltage drop. With the MOSFET as the main switch, the voltage drop is proportional to the current and is relatively low at low currents. Such a feature is very desirable for light-load efficiency. Therefore, combining the best features of power MOSFET and IGBT will ensure high efficiency at light loads and high temperatures. The basic hybridization idea is to have the power MOSFET share the current below a threshold level and the IGBT take over for the rest. In general, the current flows through the low-impedance path. Thus, when a current-associated voltage drop is lower than the fixed IGBT voltage drop, the current will flow through the power MOSFET. Such a simple idea is not appropriate for hard-switching PWM inverters because turning on one side of the switch needs to turn off the opposite side diode, which, in this case, is the internal body diode of the power MOSFET. With typical slow reverse recovery and snappy characteristic of MOSFET body diode, the penalty of the added switching loss will offset any gains on the conduction loss. Therefore, such a hybrid switch has not been adopted in the conventional hard-switching PWM inverters.

With soft switching, the diode current is always diverted to the opposite-side diode before the opposite-side switch is turned on; therefore, the switch can be turned on under the zero voltage condition. In this case, the slow reverse recovery is no longer an issue. Therefore, it is possible to adopt the hybrid switch in most zero-voltage switching (ZVS)-based inverters. The only concern is during the turn-on process, during which a majority of the load current may flow through the power MOSFET and result in transient overcurrent and associated losses. It is necessary to delay the turn-on process of the MOSFET. The turn-off delay depends on the die size of the MOSFET. If the MOSFET size is too small, turning off IGBT can easily cause MOSFET overcurrent and even result in an avalanche breakdown.

Thus, the MOSFET cannot be delayed too much during turnoff. Fig. 1 shows the circuit diagram of the hybrid switch for the phase leg of a soft-switching inverter. The -delay" block can be configured with three possible cases: 1) turn-on delay only; 2) turn-off delay only; and 3) both turn-on and turn-off delays. 


\section{International Journal of Science and Research (IJSR) \\ ISSN (Online): 2319-7064}

Index Copernicus Value (2013): 6.14 | Impact Factor (2015): 6.391

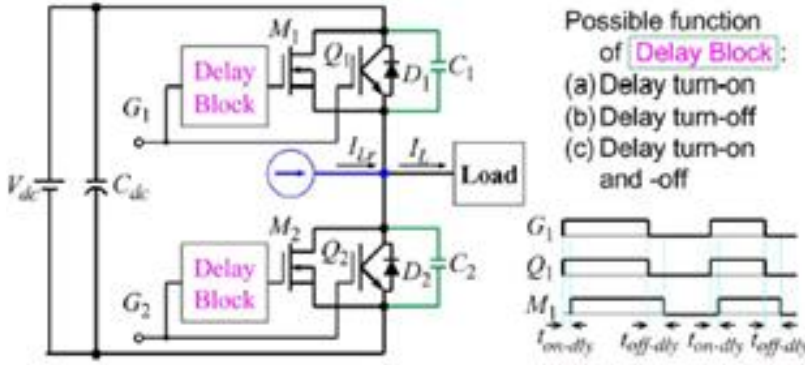

Figure 1: Hybrid switch configuration for phase leg of for a soft-switching inverter.

If the MOSFET die area is large enough, it is possible to delay the MOSFET turn-off so that the IGBT turn-off tail current induced loss is minimized. The circuit here is a generic soft switching leg that can employ different auxiliary circuits to achieve ZVS [12]-[18].

The proposed approach for a soft-switching inverter is to use the MOSFET as the main switch and the IGBT as the overflow switch.

\section{Performance of Proposed Switch in Coupled-Magnetic Type Soft-Switching Inverter}

Fig. 2(a) shows the circuit diagram and terminals of the proposed hybrid switch. Note that the conventional IGBT's anti parallel diode has been eliminated because the MOSFET die size is large enough to handle the continuous reverse current In this case, the total number of the main devices in the hybrid soft switch is the same as that in the conventional IGBT modules. Under the light-load condition, less than 100 $\mathrm{A}$ in this case, the inverter may operate mostly at lower temperatures, and the MOSFET will take over more current. Under the heavy-load condition, the IGBT will dominate, and the voltage drop is in fact decreased while temperature increases.

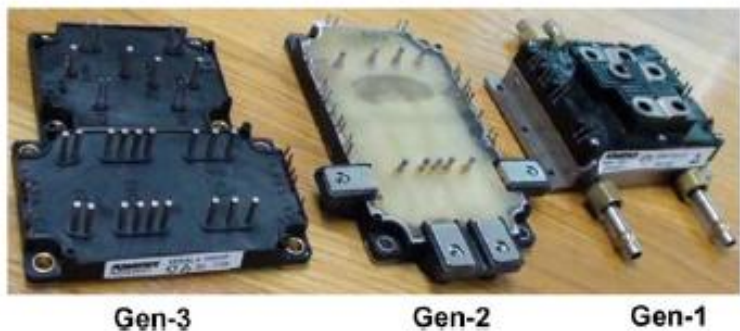

Figure 2: Photograph comparing the three generations of soft-switching module.

The first generation (Gen-1) adopted an internal bus bar structure to reduce the substrate resistance loss with the major penalty on parasitic inductance. The second generation (Gen-2) adopted a low-profile module housing to reduce the parasitic inductance, but the substrate path causes significant conducting path resistance penalty. The third generation (Gen-3) adopted two latest available larger die MDmesh power MOSFET chips in parallel with the same IGBT used in the early generations. However, the external diodes are completely eliminated to make room for the substrate area to provide sufficient conduction path. As a result, both parasitic inductance and package resistance are substantially reduced. Fig. 4 shows the photograph comparing the three generations of the hybrid soft-switching module package. The firstgeneration module adopts the integrated cooling structure. The second and third generations moved back to the conventional module that allows natural convention or forced-air cooling because the inverter built with the firstgeneration modules demonstrated ultrahigh efficiency of $99 \%$ through calorimeter testing, thus suggesting that it is possible to eliminate the extra cooling system to save the cost of both the module package and the cooling system itself .

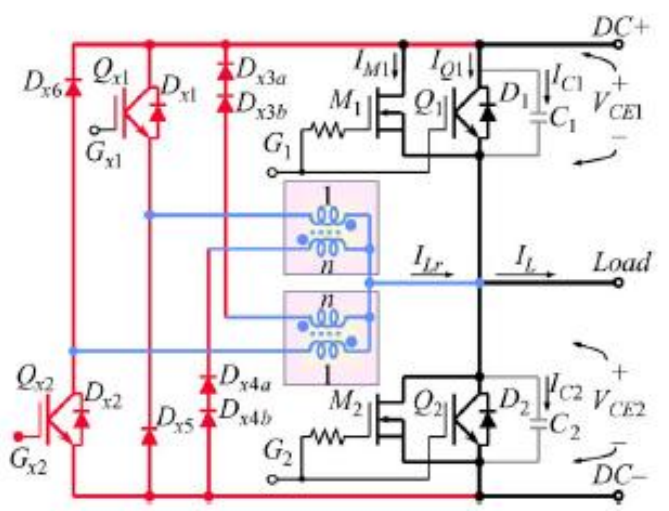

Figure 3: Use of the hybrid switch in a phase leg of the coupled-magnetic-type soft-switching inverter.

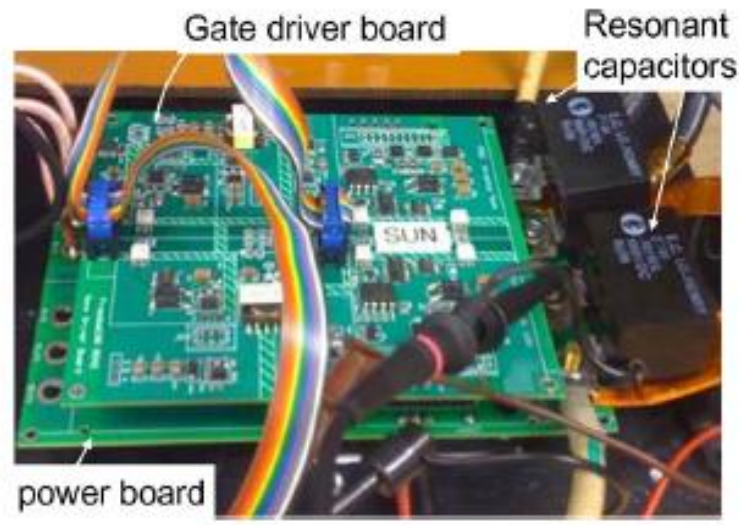

Figure 4: Photograph of the custom hybrid soft switch power and gate drive circuit boards sitting on top of the modules.

\section{Variable Timing Control of Soft-Switching Inverter}

Fig. 4 shows the photograph of the complete assembly of the power module, including a power board that connects all the power pins and a gate drive board that interfaces to the controller through ribbon cables. The copper weight and the number of layers of the printed circuit board (PCB) depend on the power requirement. In this specific design case, rather than using a heavy copper board or a multilayer board with a typical 1-oz copper, multiple four-layer standard PCBs were stacked to allow sufficient current handling capability. 


\section{International Journal of Science and Research (IJSR) \\ ISSN (Online): 2319-7064}

Index Copernicus Value (2013): 6.14 $\mid$ Impact Factor (2015): 6.391

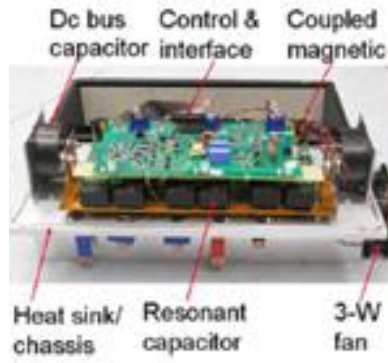

(a)

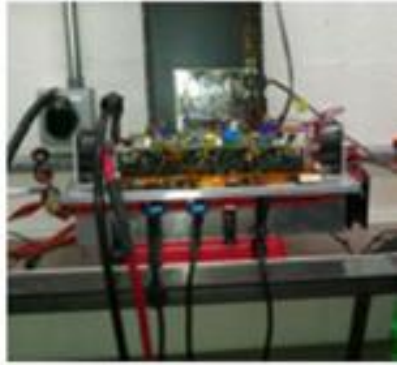

(b)
Figure 5: Photographs of a 325-V 55-kW prototype. (a) Complete inverter assembly. (b) Setup on a test stand.

With the ZVS verified in the complete load range, a complete three-phase soft-switching inverter was constructed for a traction motor drive with $325-\mathrm{V}$ nominal input and $55-\mathrm{kW}$ peak power. Fig. 10(a) shows the photograph of a 325-V 55$\mathrm{kW}$ traction drive inverter, and Fig. 10(b) shows the photograph of the inverter sitting on a test stand for dynamometer testing. The continuous power rating was specified at $30 \mathrm{~kW}$, but with ultrahigh efficiency achieved, the continuous testing was actually performed at $39 \mathrm{~kW}$ with a $3-\mathrm{W}$ fan installed to help circulate the air and serve as the base load for auxiliary power.

\section{Advantages}

1) Efficiency improvement

2) Conduction losses are reduced.

3) Switching losses are reduced.

4) MOSFET shares the current below threshold level.

5) IGBT shares the current above the threshold level.

6) Low Switching losses due to the smaller overlap of switch voltage \& current.

7) High Reliability due to the reduced stresses on the

8) switching components.

9) Reduced voltage \& current ratings for the device.

\section{Simulation Circuit}

For Hybrid soft switching inverter several power electronics switches such as IGBTs, MOSFETs se as forced commutation method. Earlier techniques such as the DC motor and Thyristor Bridge which are replaced with new techniques such as Voltage Sourced Converters (VSC) are fed by Pulse Width Modulation (PWM) to the asynchronous machine. As the flexibility of speed and torque control with DC machine, the same can be obtained by the combination of pulse width modulation technique with modern control technique such as Field Oriented Technique or Direct Torque Control methods. In this section a simulation of AC drive controlling an asynchronous machine is been described. The machine library of simulation consists of four most common three phase machine asynchronous machine. The following machine can be used either used as generating mode or motoring mode.
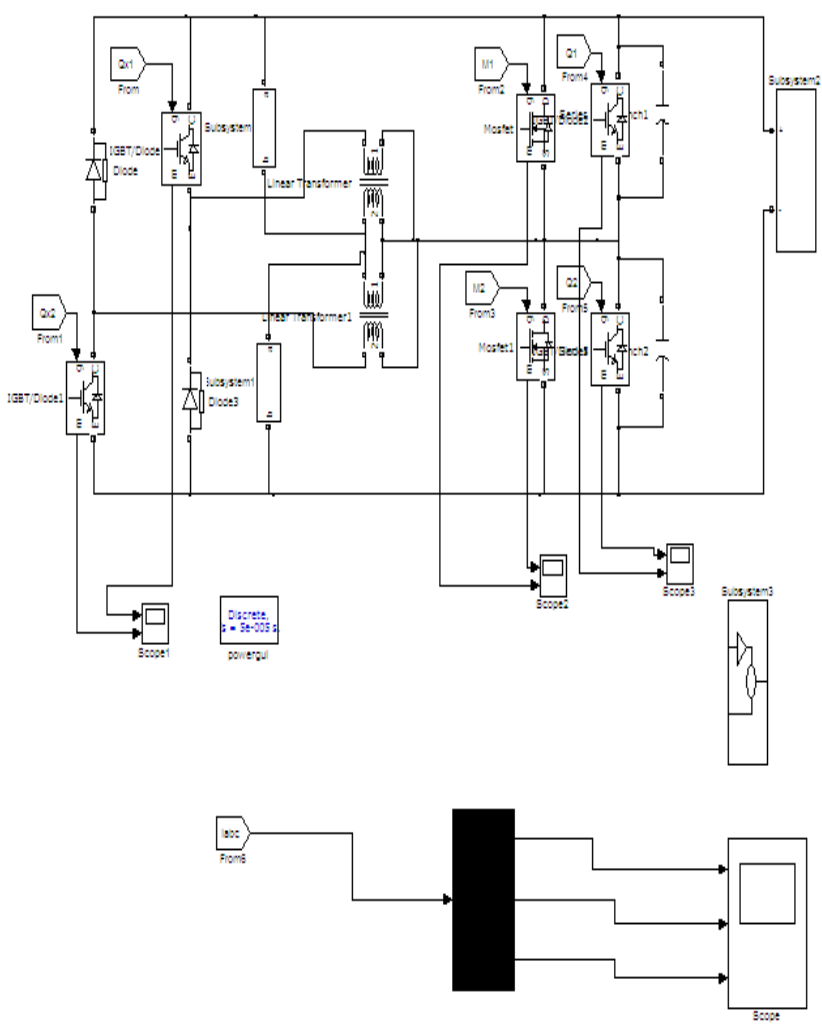

Figure 6: Simulation circuit

These machines can be used to simulate electromechanical transient in an electrical network when combined with linear and non linear elements such as transformer line loads, breakers, etc. for simulation of drives they are combined with power electronics devices. The power electronics library of simulation contains diodes, thyristors, MOSFET and IGBT. These several blocks interconnected with each other to form Three Phase Bridges. Simulation of 3 HP, 4 pole motor is done with a inverter using Pulse Width Modulation (PWM) technique. Frequency and amplitude of output voltage is varied by using PWM technique and these controlled voltage and frequency are used to control motor speed.

\section{Waveform Analysis}

Fig. 5 shows the inverter output current waveforms at 2980$\mathrm{r} / \mathrm{min} 110-\mathrm{Nm}$ motoring load under the $375-\mathrm{V}$ dc input voltage condition.

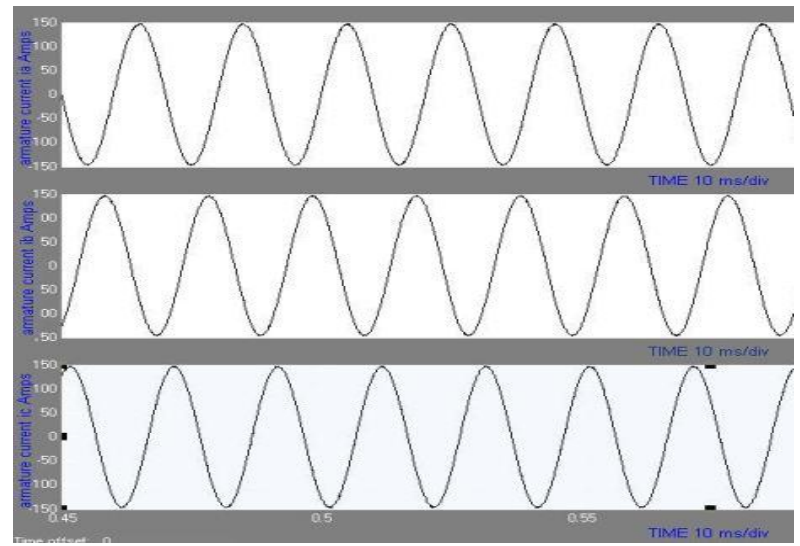

Figure 5: Inverter output current waveforms ia,ib,ic. 


\section{International Journal of Science and Research (IJSR) \\ ISSN (Online): 2319-7064}

Index Copernicus Value (2013): 6.14 | Impact Factor (2015): 6.391

\section{Efficiency of Soft Switching Inverter}

High efficiency cannot be accurately measured with a power meter that measures the dc input and PWM ac output. Some operating points, however, were verified with a differential calorimeter, which has a small chamber to serve as the reference and a large inverter chamber to house the inverter. The power loss is proportional to the ratio of the temperature difference between the two chambers. Each calorimeter test needs to be performed for more than $5 \mathrm{~h}$ to ensure that the thermal condition reached its steady state for each test point. Fig. 13 shows the coolant temperatures of the calorimeter and the corresponding inverter efficiency under the $325-\mathrm{V}$ dc input and 12.2-kW output condition.

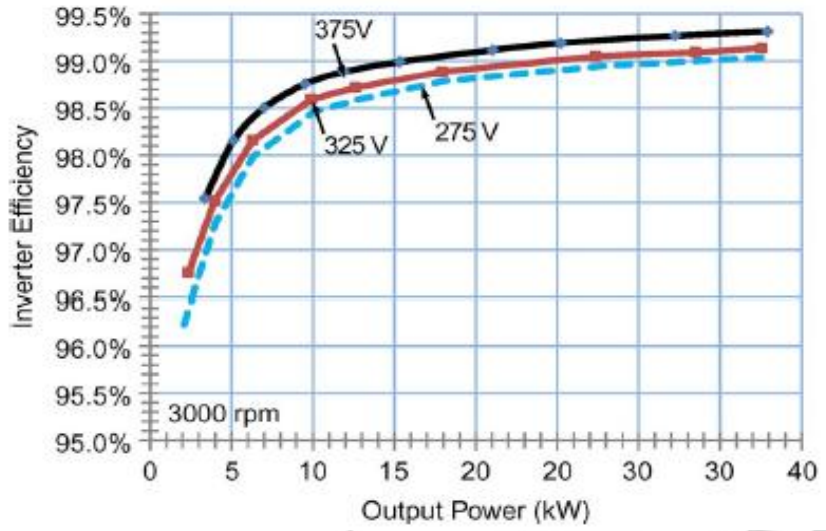

Figure 6: Measured efficiency as a function of output power at $3000-\mathrm{r} / \mathrm{min}$ operation

To further verify the efficiency numbers, a loss separation method was used to calculate individual component losses with assistant of measuring the temperatures of the module case and couple magnetic windings over a long period. Fig. 14 shows the measured power module case temperature over a 12 -min interval. The $325-\mathrm{V}$ condition was started at a temperature that was already in steady state; hence, over the 12-min interval, there was not any appreciable temperature rise. At the $20 \circ \mathrm{C}$ room temperature test condition, the entire inverter was only cooled by a $3-\mathrm{W}$ fan, and the monitored module, which is far away from the fan, has a case temperature of $47{ }^{\circ} \mathrm{C}$ under the steady-state $325-\mathrm{V}$ input and 38-kW output condition. The coupled magnetics temperatures and their corresponding losses offline, and the results were then used to project their losses under inverter

TABLE I

Loss SEPARATION AT 375-V DC INPUT AND 37.59-kW AC OUTPUT CONDITION

\begin{tabular}{|l|c|c|c|}
\hline Loss Component & Loss (W) & $\begin{array}{c}\text { Percent of total } \\
\text { loss }\end{array}$ & $\begin{array}{c}\text { Percent of input } \\
\text { power }\end{array}$ \\
\hline Main switches & 199.8 & $73.5 \%$ & $0.528 \%$ \\
\hline Auxiliary switches & 11.7 & $4.3 \%$ & $0.031 \%$ \\
\hline Auxiliary diodes & 4.3 & $1.6 \%$ & $0.011 \%$ \\
\hline Magnetics & 30.2 & $11.1 \%$ & $0.080 \%$ \\
\hline Auxiliary powers & 19.1 & $7.0 \%$ & $0.050 \%$ \\
\hline Parasitic components & 6.9 & $2.5 \%$ & $0.018 \%$ \\
\hline Total losses & 272 & $100.0 \%$ & $0.718 \%$ \\
\hline
\end{tabular}

operating conditions. The total coupled magnetic losses as a function of temperature under different ambient temperature conditions are shown in Fig. 15. Under the $375-\mathrm{V}$ dc input voltage and $37.59-\mathrm{kW}$ output power condition, the inverter output measurements showed a phase-to-neutral voltage of $143-\mathrm{V}$ rms, a peak current of $144 \mathrm{~A}$, a power factor of 0.862 , and the input power of $37.86 \mathrm{~kW}$. The individual loss components under this condition can be calculated through device conduction and switching characteristics and temperature monitoring.

The loss analysis results are listed in Table I. It should be noticed that the main power switches are the dominant loss component. Without using hybrid switch and soft switching, the main power switch loss will be much higher. With soft switching, the achieved ultrahigh efficiency is mainly attributed to the conduction voltage drop reduction by the hybrid switch. The next major loss item is the magnetic component, which accounts for $11 \%$ of the total loss in this specific case. The third major loss item is the auxiliary power supply that supplies power to the gate drives, controller, conditioning circuit, and fan with a total of $19 \mathrm{~W}$, or $7.0 \%$ of the total loss.

\section{Result}

The inverter operates under discontinuous PWM mode with a $10-\mathrm{kHz}$ switching frequency. It was tested with three voltage levels: 275,325 , and $375 \mathrm{~V}$ with a four-pole $90-\mathrm{kW}$ induction motor for electric vehicle traction drives. Fig. 5 shows the output phase current waveforms at the 1030-r/min $225-\mathrm{Nm}$ load condition. The inverter output current is $146-\mathrm{A}$ rms, and the output power is $27 \mathrm{~kW}$ under this load condition Fig.5shows the inverter output current waveforms at the $3030-\mathrm{r} / \mathrm{min} 110-\mathrm{Nm}$ load condition at $275-\mathrm{V}$ input. In this case, the inverter output current is $150-\mathrm{A} \mathrm{rms}$, and the output power is $39 \mathrm{~kW}$.

\section{Conclusion}

A hybrid switch has been proposed as the main switch of soft-switching inverters. The switch consists of the power MOSFET to conduct the low-current portion and the IGBT to conduct the high-current portion. The use of the proposed hybrid switch in a soft-switching circuit avoids the reverse recovery problem of the power MOSFET while taking advantage of the low-voltage-drop body diode with synchronous rectification. This combination not only eliminates the switching loss but also reduces the conduction loss substantially. Using the custom hybrid switch module in a variable-timing controlled coupled-magnetic-type ZVS inverter demonstrated an ultrahigh-efficiency operation over a wide load range. Experimental results with the total loss projected by the temperature rise and loss separation analysis indicate that at the nominal $325-\mathrm{V}$ input and $30-\mathrm{kW}$ output, the efficiency is $99 \%$, and at a $375-\mathrm{V}$ input and $38-$ $\mathrm{kW}$ output, the efficiency exceeds $99.3 \%$. 


\section{International Journal of Science and Research (IJSR) \\ ISSN (Online): 2319-7064}

Index Copernicus Value (2013): 6.14 | Impact Factor (2015): 6.391

\section{Acknowledgement}

The author would like to express his great thank to Mr. N. Narender Reddy (Head of the Department EEE \& Asst. Prof. of Sri Venkateswara Engineering College, India),Project Coordinator B.Venugopal Reddy ( Asst. Prof. of Sri Venkateswara Engineering College, India) \& my Staff for their valuable technical suggestion and full guidance towards completion of this paper.

\section{References}

[1] Y. M. Jian, G. C. Hua, F. X. Yang, and F. C. Lee, Softswitching of IGBT's with the help of MOSFET's," in Proc. VPEC Power Electron. Semin., Blacksburg, VA, USA, Sep. 1992, pp. 77-84.

[2] M. Borage, S. Tiwari, and S. Kotaiah, MOSFETassisted soft-switching of IGBTs: A re-examination," EE Times, pp. 1-11, Nov. 2003.

[3] J. W. Kimball and P. L. Chapman, Evaluating conduction loss of a parallel IGBT-MOSFET combination," in Conf. Rec. 39th IEEE IAS Annu. Meeting, Oct. 2004, pp. 1233-1237.

[4] K. F. Hoffmann and J. P. Kaerst, High frequency power switch - Improved performance by MOSFETS and IGBTs connected in parallel," in Proc. Eur. Power Electron. Appl., Dresden, Germany, Sep. 2005, pp. 111.

[5] J. P. Kaerst and K. F. Hoffmann, High speed complementary drive of a hybrid MOSFET and IGBT power switch," in Proc. Eur. Power Electron. Appl., Dresden, Germany, Sep. 2005, pp. 1-9.

[6] M. Frisch and T. Erno, Innovative topologies for high efficient solar applications," in Proc. Power Electron. Eur., 2009, no. 3, pp. 32-33.

[7] X. Kang, L. Lu, X. Wang, E. Santi, J. L. Hudgins, P. R. Palmer, and J. F. Donlon, Eharacterization and modeling of the LPT CSTBT-The 5th generation IGBT," in Conf. Rec. 38th IEEE IAS Annu. Meeting, Salt Lake City, UT, USA, Oct. 2003, pp. 82-87.

[8] H. Iwamoto, H. Haruguchi, Y. Tomomatsu, J. F. Donlon, and E. R. Motto, A new punch-through IGBT having a new n-buffer layer," IEEE Trans. Ind. Appl., vol. 38, no. 1, pp. 168-174, Jan./Feb. 2002.

[9] E. R. Motto and J. F. Donlon, The latest advanced in industrial IGBT module technology," in Proc. IEEE Appl. Power Electron. Conf., Anaheim, CA, USA, Feb. 2004, pp. 235-240.

[10] J.-S. Lai, W. Yu, H. Qian, P. Sun, P. Ralston, and K. Meehan, High temperature device characterization for hybrid electric vehicle traction inverters," in Proc. IEEE Appl. Power Electron. Conf., Washington, DC, USA, Feb. 2009, pp. 665-670.

[11]R. W. DeDoncker and J. P. Lyons, The auxiliary resonant commutated pole converters," in Conf. Rec. IEEE IAS Annu. Meeting, Oct. 1990, pp. 1228-1235.

[12] W. McMurrary, Resonant snubbers with auxiliary switches," IEEE Trans. Ind. Appl., vol. 29, no. 2, pp. 355-362, Mar./Apr. 1993.

\section{Author Profile}

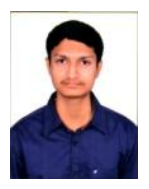

Suryapet.

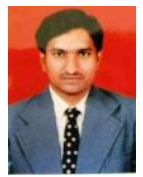

Juluri Shiva Prasad received the B.Tech. degree in Electrical Engineering from Arvindaksha educational society's group of institutions, Balemla Suryapet. He is now Presently pursuing M.Tech Power Electronics final year in Sri Venkateswara engineering college

Mr. N Narender Reddy, presently working as Assistant professor and Head of the department in Sri Venkateswara engineering college Suryapet, Nalgonda (dist),T.S. India. He did his B.Tech degree in Electrical \& Electronics Engineering, P.G in High Voltage Engineering. Currently he is pursuing his Ph.D in K L University Vijayawada. He has a teaching experience of 10 years. His area of interest includes Smart grids and micro grids.

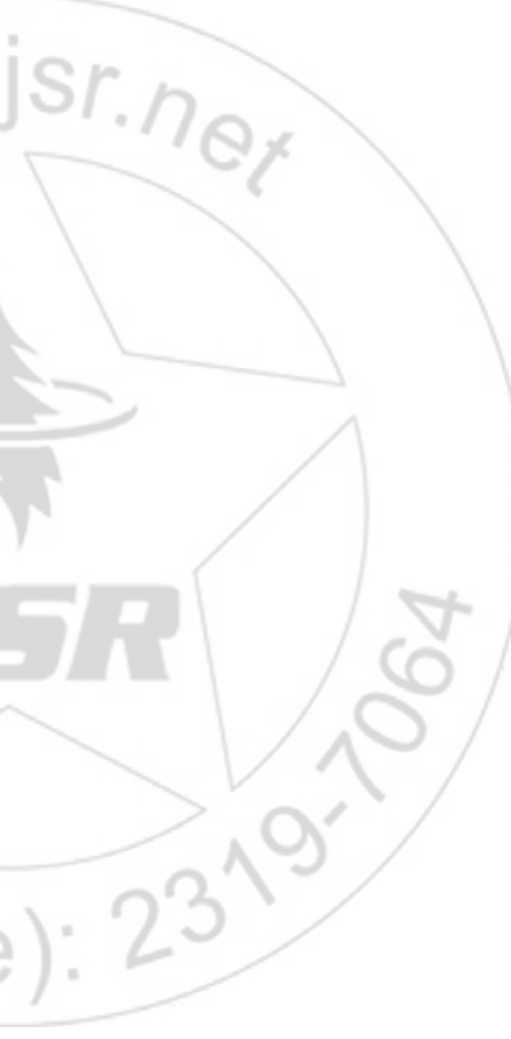

